\title{
DES-FAZER DE CORPOS: UMA HISTÓRIA SOBRE BEM-ESTAR, SOFRIMENTO E INTERSEXUALIDADE UN-DO OF BODIES: A HISTORY ABOUT WELL-BEING, SUFFERING AND INTERSEXUALITY
}

\section{Barbara Gomes Pires}

barbaragomespires@gmail.com

Doutoranda no Programa de Pós-Graduação em Antropologia Social do Museu Nacional da Universidade

Federal do Rio de Janeiro (PPGAS/MN/UFRJ).

\section{RESUMO}

$\mathrm{O}$ artigo se propõe a examinar alguns acionamentos e atravessamentos da categoria "bem-estar" segundo um caso de intersexualidade acompanhado ao longo de 2014 a partir de um trabalho etnográfico em um hospital no Rio de Janeiro. Através das abordagens clínicas deste caso, importa refletir sobre os espraiamentos e efeitos de protocolos biomédicos específicos, a saber, modos de procedimentos definidos que englobam o que chamam hoje de "distúrbios do desenvolvimento sexual". Esta história, de Marcos e também de Marta, um bebê de alguns meses de idade com uma condição diagnosticada como "hiperplasia adrenal congênita", pode nos ajudar a entender como as aplicações práticas desses protocolos se relacionam com concepções de um bem-estar restrito e funcional. A funcionalidade descrita será não só de ordem biológica, mas também social. Ao seguir essa trama biomédica, veremos como ideias de sofrimento, vulnerabilidade e qualidade de vida afetam determinadas experiências e também moldam subjetividades.

Palavras-chave: Intersexualidade. Protocolos Biomédicos. Bem-Estar.

\begin{abstract}
The article aims to examine some incitements and crossings of the category "well -being" from a case of intersexuality accompanied throughout 2014 in a hospital ethnography in Rio de Janeiro. Through clinical approaches from this case, we should reflect on the reaches and specific biomedical protocols effects, namely protocols that include what it's called now "disorders of sexual development". This story of Marcos and also of Marta, a baby a few months old with a condition diagnosed as "congenital adrenal hyperplasia" can help us understand how the practical applications of these protocols relate to conceptions of a limited and functional well-being. The described functionality is not only biological, but also social. By following this biomedical plot, we will see how ideas of suffering, vulnerability and quality of life affect certain experiences and shape subjectivities.
\end{abstract}

Keywords: Intersexuality. Biomedical Guidelines. Well-Being. 


\section{INTRODUÇÃO}

Uma visão de privação está associada a uma visão de bem-estar, diz Marilyn Strathern em "A pessoa como um todo e seus artefatos" (2014). A frase sintetiza um processo de cuidado que se consolidará ao longo do século $\mathrm{XX}$, onde a prevenção do sofrimento requer cada vez mais uma saúde integral com uma atenção especializada e, ao mesmo tempo, englobante. Protocolos, resoluções, medicamentos, anamneses, entre outros artefatos, serão produzidos e difundidos para garantir uma atenção à saúde mais holista, integrando as especificidades das doenças e sofrimentos dos pacientes a um todo que percebem como abrangentes, por exemplo, às noções que compartilhamos sobre qualidade de vida. Se esse tratamento singular para condições específicas ocorre, é certamente porque a medicina, assim como qualquer tecnologia, é reconhecida quando produz eficácia em seus resultados. Um efeito que precisa ser fixado no corpo, mas também marcado simbolicamente. Por outro lado, sempre que anunciamos alguma noção de totalidade, esta referência estará ligada a um contexto. Mais diretamente, quando enunciamos noções de bem-estar e qualidade de vida para o atendimento de um paciente com determinada condição, essas noções precisam ser tensionadas segundo seus contextos de enunciação, posto que "os tratamentos para o sofrimento humano também dependem do conceito de pessoa evocado" (Ibid., 496).

Neste sentido, a intersexualidade, ou como a literatura médica nomeia hoje de pessoas com "distúrbios do desenvolvimento sexual", constitui-se de variadas condições em que o desenvolvimento ou a determinação lógica do sexo estariam comprometidas. Em outras palavras, quando certas variações congênitas afetam a estabilização, seja gonadal, hormonal ou fenotípica, do corpo sexuado de alguém, essa variação da norma torna-se patológica. Ainda que poucas condições de intersexualidade apresentem risco de vida, todas são atendidas e tratadas dentro de uma mesma diretriz protocolar que é caracterizada pela "urgência" em seus procedimentos a fim de conformar esses corpos.

Seguindo as linhas argumentativas de Paul B. Preciado (2008), as intensificações dos processos biológicos da vida, especialmente em seu âmbito genético e molecular, e as formulações semióticas e técnicas da subjetividade sexual marcam novas formas de pensar e experimentar a humanidade. Se nesta argumentação a fabricação tecnológica de corpos sexuados não se limita aos processos individuais de enhancement físicos e mentais ${ }^{2}$ que são conhecidos e difundidos, ela existe também na forma com que essas tecnologias e saberes são produzidos e regulados. A eficácia desse regime/mercado não está somente na redução de uma experiência humana a uma lógica medicamentosa ou técnica, mas também atravessa a produção de certas "verdades" sobre o corpo humano. Neste registro, o corpo não existe sem um suporte técnico, farmacêutico, midiático e/ou político.

Por isso, ao notarmos a persistente desigualdade nos diversos espaços científicos e médicos de produção da intersexualidade, enquanto condição desviante de um suposto processo lógico do desenvolvimento sexual, percebemos sua constante vinculação às negociações globais das biopolíticas. Ou, como veremos a seguir, refletir sobre o atendimento de condições ligadas à intersexualidade não se torna apenas uma questão de saber a "localização científica do sexo", ou de mapear os gerenciamentos diários desses atendimentos hospitalares (segundo abordagens socioculturais emaranhadas nos manejos clínicocirúrgicos), mas de processos amplos sobre quais corpos são registrados como passíveis de serem tratados, justificados, medicados e normalizados. 


\section{A URGÊNCIA DO SOFRIMENTO}

A história que irei narrar neste artigo integra um conjunto de casos de intersexualidade que pude acompanhar através de um trabalho etnográfico feito ao longo de $2014^{3}$. Em um dos hospitais que me foi permitida a entrada de campo, na Zona Norte do Rio de Janeiro, conheci a história de Marcos ${ }^{4}$. Como dito anteriormente, seu caso não desempenha apenas o papel de elucidar uma atenção médica emergencial dispendida no atendimento de uma criança com aparente risco de vida, mais além, o tratamento de Marcos nos possibilita pensar sobre como transformações tecnológicas e científicas na contemporaneidade atualizam saberes e protocolos biomédicos e, mais especialmente, como estes manuais de manejo estão intimamente ligados a concepções específicas de bem -estar. Na medida em que esse bem-estar articula outras chaves analíticas fundamentais, como sofrimento, vulnerabilidade, qualidade de vida, funcionalidade, sexo e gênero, espero mapear com a história de Marcos algumas conexões de como certos discursos e técnicas serão acionadas na aplicação de um protocolo existente para tratar uma condição que, nas palavras do Conselho Federal de Medicina, é uma "urgência biológica e social".

Em um hospital público de alta complexidade no Rio de Janeiro, um bebê de um mês de vida é internado. Ele apresenta sintomas de vômitos, mal-estar e desidratação acentuada. Desde o primeiro momento à entrada na emergência, a criança, registrada com o prenome de Marcos e sexo masculino na certidão de nascimento, é tratada para o quadro de desidratação e monitorada. A fim de determinarem o tratamento específico para a enfermidade que o levou à internação, os profissionais de saúde realizaram uma série de exames. Durante a anamnese e o exame físico, os médicos constataram que os testículos do bebê não estavam palpáveis, ou seja, eles notaram que, na bolsa escrotal de Marcos, não havia tecido testicular. Desde esse primeiro momento, uma condição de intersexualidade surgiu como dúvida para a determinação diagnóstica. A "Hiperplasia Adrenal Congênita" (HAC) $)^{5}$ em sua forma clássica, ou seja, perdedora de sal, é uma condição em que o paciente é acometido por um quadro de desidratação grave que, se não tratado com urgência, torna-se um risco de vida. Então, logo que notaram a falta de testículos em Marcos, os profissionais de saúde consideraram a HAC como a possível etiologia. Em seus prontuários, nas primeiras anotações, já aparece a sigla seguida de várias interrogações. Para confirmarem o diagnóstico, solicitaram uma coleta de raspado da mucosa oral para definição da cromatina sexual do bebê, e outros exames clínicos, como dosagens hormonais e ultrassom pélvico.

Quando cheguei ao hospital, Marcos já estava internado há 20 dias. Entre conversas com residentes, a observação que mais me impactou foi em relação ao esforço médico para precisar a "ambiguidade" da genitália do bebê. De início, segundo os relatos em prontuários, a aparência da genitália dele não era ambígua, ao contrário, o pênis estava no tamanho padrão para uma criança do sexo masculino e daquela idade, com o meato urinário na ponta e fusão lábio escrotal completa. Sua bolsa escrotal era pigmentada e pregueada. Ainda assim, sua genitália não podia ser inteiramente masculina, já que não possuía os testículos. A bolsa escrotal estava vazia. Então aos olhos dos profissionais, ele não era mais um menino, ele era um bebê sem definição sexual. A diferenciação sexual volta-se, novamente, às faltas e excessos que caracterizavam a classificação e regulação da intersexualidade desde a Antiguidade ${ }^{6}$. E, mais além, volta-se à definição gonadal como parâmetro. É o primeiro passo da análise, antes de qualquer detalhamento molecular do corpo sexuado. Neste registro, não apresentar tecido testicular, mesmo com todo o "fenótipo virilizado", era indício de um problema no desenvolvimento lógico do sexo e do corpo masculino. 
Mas tal diferenciação não parecia tão brusca assim, tinha certa continuidade entre as anatomias sexuais. Pela escala biomédica, apontaram que Marcos estava com o grau de virilização "Prader V". Ela determina os graus de virilização da genitália e este nível indicava que a genitália parecia ser mais visivelmente masculina possível. Na superfície era tudo igual, a anatomia era bastante similar, exceto pela falta das gônadas, de tal forma que somente com a minúcia do exame físico foi possível detectar a ausência testicular.

A transição da localização de uma verdade sobre o sexo atravessa muitas perspectivas e formas distintas de interpretar e marcar o corpo. De um papel social generificado que evidenciava dois tipos anatômicos distintos ao comportamento e orientação sexual, há uma determinação gonadal para outra mais uma vez generificada, até uma validez cromossômica e molecular do sexo, este processo de descobrir e registrar uma verdade mantém-se como uma preocupação constante ao longo de toda história. A inquietação em saber a "verdadeira" localização do sexo em meio ao corpo imperfeito ou ambíguo não só retroalimenta buscas por uma verdade sobre o corpo, a humanidade e a realidade, mas também anda lado a lado com uma necessidade de estabilizar normais sociais.

A busca por eliminar ambiguidades, dúvidas e mal-entendidos em relação ao corpo intersexual atravessa a necessidade, nos moldes descritos por Judith Butler, em Problemas de Gênero (2008), de preservar uma inteligibilidade do sexo/gênero e uma lógica heteronormativa das práticas sexuais. Observar o gerenciamento sociomédico da intersexualidade, conforme analisou Paula Sandrine Machado (2008), pode nos dizer bastante sobre o sexo enquanto tecnologia de poder. Podemos observar, também, o que chamei, inspirada em formulações foucaultianas, de processo de veridicção da intersexualidade ${ }^{8}$, onde não só o caráter administrativo do atendimento médico, mas também o caráter produtivo da ciência médica, se atualizam em suas técnicas e abordagens a fim de assegurarem a fabricação e regulação de "verdade" sobre o corpo sexuado e intersexual.

Em sua tese, Machado (Ibid.) já havia alertado para os perigos que uma vinculação não crítica da saúde (nos moldes dos direitos reprodutivos) enquanto direito sexual e humano significa para a experiência da intersexualidade. As práticas de "normalização" aparecem, segundo os registros biomédicos, como garantias de direito para as pessoas intersexuais. Os profissionais de saúde que acompanhei neste e em outros casos se comprometem com esta interpretação, investem diariamente na materialização desse "direito à saúde" enquanto "direito humano". Eles acreditam nesses atendimentos. De modo que as formulações sobre a "verdade" do sexo/gênero de alguém e dos direitos e acessos à saúde pautam-se em interseccionalidades que não se fazem visíveis nos guidelines, mas sim nesses gerenciamentos cotidianos. O processo de veridicção ocorre além das moléculas, gônadas e hormônios, atravessam concepções generificadas, valores socioculturais, vulnerabilidades e desigualdades, que modificam os sujeitos de direitos de uma "humanidade sexuada".

Dito isto, com o resultado prévio do sexo cromossômico através do exame da cromatina sexual ${ }^{9}$, os médicos autorizaram uma nova coleta, desta vez, de sangue, para análise citológica e uma definição mais fidedigna do cariótipo. Ainda que a "urgência" da resolução biomédica mobilize uma precocidade nos atendimentos e procedimentos que envolvam estes casos, a certeza diagnóstica não poderia ser apressada, pois ali constava a verdade molecular do sexo. Então, quando sai o resultado do cariótipo do bebê, confirmando o sexo cromossômico de 46, XX, o diagnóstico de HAC também é definido. Este resultado associa-se a outros exames, como suas taxas de hormônios androgênicos elevados, o que comprovava a tese da produção excessiva de andrógenos pela suprarrenal. Os médicos atuantes no caso, das áreas de pediatria, genética, endocrinologia e psicologia, providos de vários tipos de exames e com um diagnóstico fechado, 
decidiram realizar uma reunião multidisciplinar para formular o prognóstico e os tratamentos subsequentes da criança.

Na reunião multidisciplinar, percebi que, para os profissionais de saúde, a questão clínica mais emergencial estava resolvida - a desidratação havia sido tratada. Para evitar que outras crises ocorressem, era preciso dar ao paciente doses de um hormônio esteroide do tipo "glicocorticoide" para regular a insuficiência adrenal e suprimir a produção excessiva de hormônios androgênicos. Assim, a virilização iria parar bem como a perda de sal gerando reflexos de desidratação. A hormonoterapia nos pacientes com HAC, na forma clássica, é praticada ao longo de toda a vida. De modo que o mais grave e necessário, disse um dos endocrinologistas na reunião, era buscar um consenso médico sobre a designação sexual.

Decidir sobre a designação sexual da criança era o ponto nevrálgico da reunião. Enquanto uns médicos apontavam para o fato de que as cirurgias feminizantes necessárias para a "correção" da genitália de Marcos não eram simples, pois além dos procedimentos serem arriscados, também podiam provocar fístulas, estenose, entre outros resultados deletérios no corpo do bebê. Como resume bem uma das geneticistas ${ }^{10}$ do caso:

\footnotetext{
"Ele é muito virilizado, ele era um caso raro. Então a gente fez a reunião porque a grande dúvida é o que que faz... Se tira os ovários, não tira. E aí assim, o que eu andei lendo, pelo menos, era que tinha que intervir o mínimo possível. É o que a gente estava questionando nesse menino, no Marcos, era justamente isso. O ex Marcos, né. Era que tudo bem que a conformidade com o gênero feminino é maior, mas a cirurgia é muito difícil. É uma cirurgia complicada, que nem sempre dá um resultado final bom. Pode sentir dor na relação sexual. Que vira uma vagina, né. Quando é muito virilizado parece que é mais difícil, porque eles pegam o clitóris e invertem, para não tirar, senão a pessoa não vai ter sensibilidade nenhuma. Se é muito grande, como você vai conseguir inverter aquilo? Não dá. O problema é que tem que manter a ponta, né, é a ponta que é sensível. Mas não sei o que eles fazem. Pode ter muita estenose, fica apertado demais, tem dor. E a cirurgia era contra. Ele era a favor de deixar como menino."
}

Outros médicos insistiam no protocolo para esta etiologia, isto é, em casos de pacientes 46, XX com HAC a designação deve ser necessariamente para o sexo feminino, não importando o grau de virilização ${ }^{11}$. Ao mesmo tempo em que essa controvérsia se desenrolava, com argumentações clínicas e técnicas sendo acionadas em ambos os lados, um consenso se delineava e se espraiava. Entre as falas dos profissionais de saúde, uma retórica sobre funcionalidade se fortalecia para justificar e legitimar a redesignação do bebê. Em meio às complicações sobre as possibilidades de tratamento e intervenção, certo bem-estar é acionado. Um bem-estar atrelado a uma noção funcional do corpo humano, tanto em seu âmbito reprodutivo quanto sexual.

Conforme Machado também descreve a partir de sua própria etnografia em hospitais, a função reprodutiva que é acionada pelos médicos remete à capacidade de fertilidade, enquanto a função sexual relaciona-se ao estímulo hormonal, por exemplo, o aumento do pênis e a possibilidade de ereção, para os homens, ou a não-virilização, para as mulheres (Ibid., 129-130). O que importava, neste caso, seria adequar a designação do sexo social ao sexo cromossômico e às gônadas femininas. Pois mesmo com o grau máximo de virilização, a genitália de Marcos nunca seria considerada completamente masculina, não sem o tecido testicular para manter a produção de hormônios sexuais, desenvolver os caracteres secundários durante a puberdade e garantir a funcionalidade reprodutiva. Por isto a terminologia utilizada pelos profissionais para referir-se ao 
paciente ainda era de "genitália ambígua". A marca da fertilidade era imprescindível, como afirmou outra endocrinologista durante a reunião multidisciplinar.

A garantia de fertilidade (e consequentemente, mas de forma encapsulada no discurso, a garantia de heterossexualidade) comprimiu as diversas argumentações no consenso protocolar e foi suficiente para convencer os pais da redesignação sexual. Das indicações médicas para a família, uma é fundamental para o entendimento dessas práticas como um dos eixos de produção de subjetividade: pediram para os pais levarem a criança com roupa rosa na próxima consulta. Antes, nos dias de internação na enfermaria pediátrica, a mãe só o vestia com roupas azuis. Sugeriram também que a família desse outro nome ao bebê - o prenome e o sexo no registro civil só poderiam ser alterados por meio de decisão judicial, e é necessário um laudo médico explicando a condição de intersexualidade para justificar a modificação do registro, mas a equipe médica já indicava para a família chamar o "antigo" Marcos por um nome e gramáticas femininas. Em casos assim, um dos profissionais de saúde me confessou, não adiantava de nada a decisão médica de designar para o sexo feminino se a família não reforçasse este sexo social cotidianamente.

Após a definição do prognóstico e seus encaminhamentos na reunião multidisciplinar, o bebê teve alta da enfermaria pediátrica pelo quadro de desidratação, retornando somente para consultas a fim de intervirem na designação sexual escolhida. Agora não era mais chamado de Marcos, mas de Marta. Depois de uns quatro meses desde a internação a família foi encaminhada com a criança para a urologia e cirurgia pediátrica. A última informação que obtive antes de finalizar a etnografia foi em setembro de 2014 através de um dos endocrinologistas pediátricos que acompanharam o caso: "a genitoplastia ${ }^{12}$ ", ele disse, "tem que ser realizada antes dela completar 1 ano de idade". Nesta interpretação, a precocidade cirúrgica é justificada pelo bem-estar psicossocial do paciente e de seus familiares. Enquanto não existir uma congruência entre o fenótipo, representado aqui pela "genitália ambígua", e o sexo cromossômico e gonadal do paciente, haveria uma sensação de angústia que não permitiria esse bebê ser aceito e socializado plenamente. Esta é a "urgência social" que aparece na resolução do Conselho Federal de Medicina e em outros protocolos biomédicos internacionais sobre o tema. Para que a inserção social ocorra, para que exista inteligibilidade social sem ruídos e ambiguidades, é preciso que o dimorfismo sexual seja reiterado o mais breve possível e continuamente. Marta terá que passar por diversas cirurgias reparadoras durante a puberdade, para aperfeiçoar o resultado cosmético e funcional de sua genitália, e mesmo assim não há garantia de que um desempenho funcional e sexual satisfatório se concretize. O próprio guideline-base sobre o tema critica a falta de estudos, a longo prazo, que possam confirmar (e legitimar, por isso há uma cobrança) a proeminência dada à intervenção cirúrgica dentro do manejo da intersexualidade (LEE et al, 2006).

Em resumo, os corpos intersexuais tornam-se inteligíveis (e consequentemente funcionais, reprodutivos e humanos) quando passam pelo crivo biomédico, através dessas reposições hormonais e intervenções cirúrgicas. Contudo, importante frisar que não é papel único da biomedicina "gestar e gerir"13 esses corpos e vidas, apesar de que o privilégio da explicação e do cuidado dessas pessoas atravessa, em grande medida, as dinâmicas biomédicas. A necessidade de produzir homens e mulheres, distintos em suas biologias, documentos e atuações sociais está difundida culturalmente, o que interessa comentar aqui é o valor particular que está em jogo quando critérios de bem-estar, funcionalidade e qualidade de vida são acionados para o atendimento dessas condições. De tal forma que essas práticas médicas descritas devem ser reconhecidas dentro de um arsenal discursivo de produção de corpos e subjetividades e não, 
simplesmente, como encaminhamentos necessários, neutros e naturais para a designação correta e coerente do sexo de uma pessoa.

São muitas as dificuldades e complicações deste tipo de intervenção, mesmo em pacientes adolescentes ou adultos que não apresentem desconfortos posteriores com o sexo designado na infância. Não precisamos nem mesmo discutir a "correção" cirúrgica precoce como prática invasiva e irreversível ${ }^{14}$, a própria reposição hormonal é tida como um "desafio" já que é "imperfeita e não mimetiza a secreção fisiológica" dos hormônios, podendo levar, por exemplo, a outra "desordem endócrina" como nos casos de hipercortisolismo ${ }^{15}$ (GILBAN, 2013, p. 5).

Se por um lado parece fundamental notar que houve um avanço no cuidado e na atenção médica, já que algumas décadas atrás o protocolo era o de intervir precocemente sem discussão crítica entre as especialidades e praticar o ocultamento de informações para pais e paciente. Por outro lado, modelos de intervenção cirúrgica ainda estão sendo seguidos precocemente, fechando possibilidades futuras ao determinar marcas de gênero e integridades corporais específicas para crianças intersexuais. A controvérsia entre os médicos na reunião multidisciplinar perde relevância em favor do protocolo. "Eu acho que a maioria das vezes as pessoas não pesam muito, fazem, porque o consenso é esse e pronto", comentou uma das geneticistas do caso. Preterir autonomia e autodeterminação em favor de supostas coerências funcionais e normalizadoras, ainda hoje é o caminho protocolar.

\section{A INCERTEZA DO BEM-ESTAR}

O distanciamento estabelecido pelo protocolo torna-se mais evidente quando retornamos à ideia de bem-estar como horizonte biomédico. Um objetivo, praticamente metafísico que, ao seguir uma suposta neutralidade técnica e expertise médica, termina invisibilizando a relação que afeta nesses atendimentos e dinâmicas hospitalares, o sofrimento (vivido, não apenas como uma retórica de finalidade clínica) dos pacientes e seus familiares. Para Kenneth Rochel de Camargo Jr (1992), essas dinâmicas imprimem um atrito entre a experiência da práxis médica (do conhecimento objetivo e restrito, mas atravessado por orientações particulares da subjetividade de cada profissional de saúde) e a experiência do sofrimento do paciente e sua família.

Em Telles-Silveira et al (2009), um grupo de médicos de várias especialidades avaliaram qualitativamente as dificuldades de comunicação entre os atores envolvidos nos atendimentos de HAC. Entrevistaram médicos, familiares e pacientes em um hospital de São Paulo e, enquanto os primeiros reclamavam da "passividade" dos últimos nas consultas, os autores observaram que é preciso cautela com essa declaração. Argumentam que as dinâmicas de ambulatórios de hospitais-escolas aprofundam a falta de cuidado centrado no paciente, não permitindo conversas mais abertas com os familiares. Esses, por sua vez, também não sabem se explicar para seus filhos e filhas em atendimento, que terminam por internalizar ainda mais sofrimentos e angústias em meio à teia biomédica de determinação sexual.

Podemos observar tal "tensão estruturante", conforme aponta Octavio Bonet (2004) sobre o trabalho da clínica, também, neste caso. Os passos até fechar o diagnóstico e decidir o prognóstico do bebê eram esclarecidos diariamente à família, especialmente para a mãe, que era a familiar que sempre estava presente durante a internação da criança. Enquanto a mãe era do lar, o pai trabalhava em um restaurante, mas faltava ao trabalho ocasionalmente durante 
o tempo de internação para acompanhar as explicações e os gerenciamentos médicos do caso. Como neste caso tive acesso estrito aos médicos, não foi possível apontar com maior clareza os impactos deste processo na família. Sabia, através dos prontuários, reuniões e salas de estudo o que acontecia, de modo que os profissionais me descreviam que "dúvidas preliminares" tinham sido esclarecidas à família, isto é, de que existia uma complicação na definição sexual do bebê, sem especificar muitos detalhes sobre a etiologia e seus significados.

Havia uma psicóloga que acompanhava a mãe ao longo da internação, pois, além da angústia derivada da falta de determinação sexual de Marcos/Marta, tinham dado esta notícia no meio da enfermaria pediátrica, onde todas as outras crianças ficam internadas juntamente de seus familiares, o que gerou um mal-estar enorme na mãe e com a família. $\mathrm{O}$ ambiente hospitalar, especialmente este, por também ser um hospital-escola, torna-se um lugar de proliferação das possibilidades de estigmatização se não houver espaços e condutas "seguras", ou melhor, se não houver um manejo atento para essas desigualdades e seus efeitos. Neste caso, o drama da "urgência" irrompeu mais pelo limbo social causado pela falta de definição sexual do que pelo risco agudo de desidratação do bebê - representadas relacionalmente pela impossibilidade de explicação materna do que acontecia com a criança para familiares e desconhecidos da enfermaria e acentuadas com os vagos esclarecimentos preliminares por parte dos médicos.

Uma abordagem pertinente nesta trama hospitalar entre bem-estar e sofrimento relaciona-se à compreensão da vulnerabilidade como uma condição compartilhada, tal como Judith Butler reflete em Undoing Gender (2004). Em outras palavras, perceber o corpo sexuado como localização e verbalização da vulnerabilidade que estrutura a humanidade levaria a um gerenciamento sociomédico desses casos de intersexualidade com maior reconhecimento na complementariedade do sofrimento e da exposição do outro. Igualmente, se dar conta de tamanha vulnerabilidade, manifestada aqui pela falta de um marcador fundamental para garantia de sociabilidade, o sexo/gênero, torna mais compreensível a atitude materna em se calar diante do limbo de inteligibilidade - a não definição sexual de seu bebê - do que consentir com a exposição e, possivelmente, com a espetacularização dessa mesma vulnerabilidade.

Experiências de sofrimento e de vulnerabilidade tais como esta nem sempre são possíveis de serem verbalizadas publicamente. O evento extraordinário que nos relata Veena Das (2007) e que reformula os investimentos morais e afetivos dos sujeitos, também modifica a maneira com que essas pessoas restituem ao ordinário esta experiência de dor ou de angústia que desestabiliza suas próprias narrativas e linguagens do cotidiano. Neste sentido, vejo sua formulação do trabalho do tempo aqui não como um trabalho de produzir coerências ou apagar incertezas, mas como um trabalho de reabitar o cotidiano quando "o sentido de ser 'humano' é testado" e a própria "linguagem corrente falha ou simplesmente não existe" (1999, p. 41).

Outro relato da psicóloga em prontuários, que foi repetido durante a reunião multidisciplinar, era de que o irmão mais velho de Marcos/Marta estava inquieto, sempre perguntando do "irmãozinho", o que parecia aprofundar ainda mais a angústia materna. A psicóloga fez alguns pedidos de acompanhamento para levar o outro filho até à enfermaria para visita. Fato que não aconteceu, pois liberaram o bebê assim que os pais consentiram com a redesignação sexual.

Podemos refletir sobre as angústias destes trâmites de determinação sexual e os limites da promessa de bem-estar. Os pais aceitarem à opção protocolar dos profissionais de saúde, em que a funcionalidade ganha relevância, pode ser sim uma questão de confiança, uma aceitação completa da justificativa biomédica sobre o corpo de sua filha - o que Anthony Giddens chama de con- 
fiança, ou de segurança ontológica, na expertise e nos sistemas abstratos. Mas também pode ser apenas um aceno momentâneo contra a incerteza, na tentativa de finalizar o sofrimento presente ao longo dessas dinâmicas e procedimentos, pois fica claro que a coerência desejada pelos protocolos não é alcançada e a incerteza envolvida nas tramas de definição do sexo/gênero desta criança não irá sumir. Como afirmou um dos médicos, a necessidade de reforçar o sexo social é uma tarefa cotidiana, evidenciando o peso do caráter sociocultural nessas determinações. A negociação parental/médica com (e contra) a incerteza demonstra que a confiança nessa coerência científica do sexo e nas intervenções clínicas e cirúrgicas são parciais e, muitas vezes, porosas.

Por mais que exista uma necessidade de assistência médica integral, inclusiva e mais "centrada no paciente" em relação aos casos de intersexualidade, que se justificam a partir de categorias supostamente totalizantes como o bem-estar, importa esclarecer como as técnicas e abordagens do saber e da prática médica são atualizadas quando esbarram nessas situações de limiaridade social. Quando a falta de esclarecimento e consentimento mais efetivo, a intervenção cirúrgica precoce ou a repetição de integridades corporais específicas são algumas das variáveis que desvelam como a hegemonia e o privilégio deste discurso ainda marca excessos e faltas na produção de subjetividades e verdades sobre certos corpos sexuados. O processo de veridicção da intersexualidade atravessa guidelines e protocolos de manejo que influenciam sim as dinâmicas decisórias dos profissionais de saúde em casos de "genitália ambígua", normalizando e humanizando esses corpos para que sejam entendidos, reconhecidos e socializados; ainda que essas demandas também surjam de familiares, de conhecidos, de estranhos e da sociedade. Por isso percebemos neste relato duas linhas se cruzando e se retroalimentando continuamente, por um lado, um emaranhamento de angústias tipicamente sociais, em relação aos códigos de cor, roupas e gramáticas de gênero, à vulnerabilidade social, à identidade de gênero ou à prática sexual relacionada à fecundidade; e, por outro lado, saberes e tecnologias biomédicas que são postas em ação nesses encontros hospitalares.

O fio condutor dos dois caminhos está centrado na relação entre sofrimento e bem-estar, marcando o dimorfismo sexual enquanto valor do corpo humano. Mas, enquanto a expertise médica aciona discursos de bem-estar normativos para legitimar intervenções clínicas e cirúrgicas precocemente, as experiências de sofrimento dessas crianças intersexuais, e de seus familiares, não cessa. A possibilidade de sofrimento não é apagada pois não há como fugir da incerteza biológica e social que essas condições carregam em nossas realidades. Pessoas intersexuais poderão, no futuro, assumir uma orientação sexual não heterossexual ou entrar em processo de transgeneridade contra o diagnóstico inicial. Elas também irão carregar as marcas dessas intervenções ao longo do tempo, precisando manter um acompanhamento clínico contínuo, seja através das hormonoterapias ou pelos reparos cirúrgicos.

Sem garantias ou follow-up, os protocolos de intersexualidade na verdade aprofundam o ciclo de sofrimento dessas pessoas. Tal qual a noção de "carreira moral" proposta por Erving Goffman (1996), em que a série de mudanças vividas por pessoas dentro de instituições hospitalares alteram efetivamente suas percepções de si e dos outros, concluo que tais práticas clínicas e cirúrgicas feitas precocemente só intensificam os processos de incertezas sobre o sexo/gênero. A garantia de coerência sexual se constrói inversamente ao apagamento ou à "mortificação do eu" intersexual. Os efeitos das práticas e explicações dessas condições constituem os processos de veridicção da intersexualidade e do corpo sexuado em geral.

Não acho, por outro lado, que esses corpos e vidas se desmaterializam completamente com as aplicações hormonais e os cortes de bisturi. Como descobrimos em diversos trabalhos etnográficos e nas próprias biografias e artigos 
de pessoas intersexuais ${ }^{16}$, a reinvenção da vida dessas pessoas estranhas à norma se torna um trabalho contínuo de restituição, visibilidade, aceitação e enfrentamento. Experiências como as de Marta desvelam, portanto, os jogos de saber e poder intrínsecos aos regimes de inteligibilidade ocidental e moderna, tais como moldam nossas realidades. Talvez, com esta história e outras mais possamos iluminar criticamente essas representações científicas e intervenções médicas ao tentarem conformar corpos "ambíguos", ao serem "des-feitos" (PINO, 2007), em corpos inteligíveis, funcionais e humanos; onde, muitas vezes, a tradução dessas certezas e coerências suscitam-se (ainda que atrelada a um ideal de bem -estar englobante) através de protocolos normalizantes, rupturas de experiências e violações subjetivas e corporais.

\section{NOTAS}

${ }^{1}$ Nova terminologia diagnóstica da intersexualidade difundida atualmente na literatura médica. Para ler a publicação do Consensus Statement que definiu a nova classificação, ver Lee et al (2006).

${ }^{2}$ Nesta vertente biomédica, como diz Rohden, Russo e Giami (2014), "percebemos a tendência de ampliar as possibilidades e os usos dos fármacos, de modo a borrar cada vez mais a fronteira, já um tanto imprecisa, entre tratamento e aperfeiçoamento (enhancement)", difundindo a ideia de que é necessário e possível agir para atingir uma performance ou um tipo de bem-estar corporal e mental específico.

${ }^{3} \mathrm{O}$ contexto mais geral desta etnografia integra minha pesquisa de mestrado, Distinções do Desenvolvimento Sexual: percursos científicos e atravessamentos políticos em casos de intersexualidade, defendida no começo de 2015. Este artigo constitui então uma versão reduzida do capítulo três, "Vidas verificadas, sofrimentos vividos".

${ }^{4}$ Todos os nomes etnográficos apresentados ao longo do artigo serão nomes fictícios.

${ }^{5}$ A HAC é considerada uma doença que resulta na deficiência da enzima 17 $\alpha$-hidroxilase ou $11 \beta$-hidroxilase produzida no córtex adrenal. "A ausência ou inatividade funcional dessa enzima impede a produção normal de cortisol e de aldosterona, desviando os produtos intermediários acumulados para a síntese excessiva de andrógenos", isto é, hormônios como a testosterona. A literatura médica ainda indica que a combinação dessas variações congênitas, que se manifestam desde o período intrauterino, são "responsáveis pelo surgimento, ao nascimento, de um quadro clínico clássico na criança: genitália externa ambígua com vários graus de virilização (nas meninas) e macrogenitossomia (nos meninos)" (Telles-Silveira et al, 2009, p. 1113).

${ }^{6}$ Para este detalhamento ver, por exemplo, Laqueur (2001), Leite Jr (2008) e Pires (2015).

${ }^{7}$ De acordo com a indicação nos prontuários e na literatura médica consultada, a genitália do bebê seria um Prader V, o que significa fusão lábio escrotal completa e uretra peniana, uma virilização que ocorre com 11 semanas de vida intrauterina (Damiani et al, 2001, 43).

${ }^{8}$ Os processos, regimes ou modos de veridicção da intersexualidade estão enraizadas nas análises de Michel Foucault (2008) sobre a biopolítica, mais especificamente suas análises sobre poder e conhecimento, além dos escritos sobre a sexualidade. Em uma conjuntura histórica, com muitas facetas se entrelaçando e em conflito, ao mesmo tempo em que se atualiza a maneira com que a verdade é contada e registrada, formas específicas de inteligibilidade e de subjetividades serão postas em jogo de acordo com essas discursividades, neste caso, sejam elas biomédicas ou dos próprios sujeitos intersexuais e seus familiares.

${ }^{9}$ As células contadas tinham corado, sugerindo que os corpúsculos de BARR (a tal da "cromatina sexual") estavam presentes e inativos. Esse procedimento só ocorre em pessoas com pelo menos um cromossomo $\mathrm{X}$ no par de cromossomos sexuais, por exemplo, $46, \mathrm{XX}$ ou 47, XXY, exatamente porque o cromossomo X não ativo, que sobra, espiraliza-se ao inativar - e torna-se o corpúsculo de BARR visualizado no exame.

${ }^{10}$ Esta foi a única entrevista semiestruturada que realizei durante o trabalho de campo, os outros comentários de profissionais de saúde descritos em aspas foram feitos mais 
livremente a partir das anotações etnográficas, sendo de minha inteira responsabilidade.

${ }^{11} \mathrm{O}$ protocolo atual confirma a obrigatoriedade das cirurgias feminizantes nesses casos: "The vast majority of genetic females affected with classic congenital adrenal hyperplasia $(\mathrm{CAH})$ have female gender identity and behavior, tomboyish play and male occupational preferences notwithstanding. In addition, most affected women can bear healthy offspring, if desired. This rationale is the basis for the suggestion that severely virilized (Prader stage $\geq 3$ ) females be considered for clitoral and perineal reconstruction in infancy" (Speiser et al, 2010, 3).

12 Termo para uma cirurgia feminizante que engloba reconstruções clitorianas e vaginais, como a clitoroplastia e a vaginoplastia.

${ }^{13}$ Como debatido por Souza Lima (2002), as diferenças do exercício do poder tutelar do Estado podem ser compreendidas a partir do binômio "gestar e gerir". Neste sentido, o primeiro termo define as práticas produtivas de variadas instituições relativas à existência e conformação de determinado corpo social, enquanto o último termo remete aos controles administrativos cotidianos destas pedagogias.

${ }^{14}$ Para ver uma discussão sobre as práticas de intervenção tecnológica-cirúrgica aplicadas sobre os corpos intersexuais com objetivos de "correção", e uma comparação desta prática com outras de "mutilação genital”, ver Knauth, Machado (2013).

${ }^{15}$ O principal glicocorticoide usado no tratamento de pacientes com HAC é o "cortisol", que em sua forma sintética é chamado de "hidrocortisona". A reposição excessiva desse hormônio ou de outros tipos de glicocorticoides pode desencadear uma supressão no crescimento que levaria a "prejuízos ao crescimento linear e maturação fisiológica do paciente" (Gilban, 2013, 5).

${ }^{16}$ Ver, por exemplo, Cabral $(2005,2009)$ e Morland (2008, 2014).

\section{REFERÊNCIAS}

BONET, Octavio. Saber e Sentir: uma etnografia da aprendizagem da biomedicina. Rio de Janeiro: Fiocruz, 2004.

BUTLER, Judith. Undoing Gender. New York: Routledge, 2004.

. Problemas de Gênero: feminismo e subversão da identidade. Rio de Janeiro: Civilização Brasileira, 2008.

CABRAL, Mauro. Cuando digo intersex. Un diálogo introductorio a la intersexualidad. Cadernos Pagu, v. 24, Jan-Jun., p.283-304, 2005.

(ed.). Interdicciones: escrituras de la intersexualidad. Córdoba:

Anarrés, 2009.

CAMARGO JR, Kenneth Rochel de. (Ir)racionalidade Médica: Os Paradoxos da Clínica. Physis, v. 2, n. 1, 1992.

Conselho Federal de Medicina. Resolução n. 1.664. Dispõe sobre as normas técnicas necessárias para o tratamento de pacientes portadores de anomalias de diferenciação sexual. Publicada no DOU n. 90, Seção 1, 13 Mai., p. 101-102, 2003.

DAMIANI, Durval; SETIAN, Nuvarte; KUPERMAN, Hílton; MANNA, Thaís D; DICHTCHEKENIAN, Vaê. Genitália Ambígua: Diagnóstico Diferencial e Conduta. Arq Bras Endocrinol Metab, v. 45, n. 1, Fev., 2001.

DAS, Veena. Fronteiras, Violência e o Trabalho do Tempo: alguns temas wittgensteinianos. Revista Brasileira de Ciências Sociais, v. 14, n. 40, p. 31-42, 1999.

. Life and Words: Violence and the descent into the ordinary. Berkeley: University of California Press, 2007.

FOUCAULT, Michel. O Nascimento da Biopolítica. São Paulo: Martins Fontes, 2008.

GIDDENS, Anthony. III. In: GIDDENS, Anthony. The Consequences of Modernity. Stanford: Stanford University Press, p. 79-111, 1990.

GILBAN, Daniel. Qualidade de Vida relacionada à Saúde de crianças e adolescentes com Hiperplasia Adrenal Congênita. Dissertação. (Mestrado 
em Endocrinologia) Programa de Pós-Graduação em Medicina, Universidade Federal do Rio de Janeiro, Rio de Janeiro, 2013.

GOFFMAN, Erving. Manicômios, Prisões e Conventos. São Paulo: Perspectiva, 1996.

KNAUTH, Daniela Riva; MACHADO, Paula Sandrine. Corrigir, prevenir, fazer corpo: a circuncisão masculina como estratégia de prevenção do HIV/ AIDS e as intervenções cirúrgicas em crianças intersex. Sexualidad, Salud y Sociedad, v. 14, p. 229-241, 2013.

LAQUEUR, Thomas. Inventando o Sexo: corpo e gênero dos gregos a Freud. Rio de Janeiro: Relume Dumará, 2001.

LEE, Peter A; HOUK, Christopher P; AHMED, S Faisal; HUGHES, Ieuan A. Consensus Statement on Management of Intersex Disorders. Pediatrics, v. 118, n. 2, 2006.

LEITE JR, Jorge. Nossos corpos também mudam: sexo, gênero e a invenção das categorias "travesti" e "transexual" no discurso científico. Tese. (Doutorado em Ciências Sociais) Departamento de Ciências Sociais, Pontifícia Universidade Católica, São Paulo, 2008.

MACHADO, Paula Sandrine. O Sexo dos Anjos: representações e práticas em torno do gerenciamento sociomédico e cotidiano da intersexualidade. Tese. (Doutorado em Antropologia Social) Programa de Pós-Graduação em Antropologia Social, Universidade Federal do Rio Grande do Sul, 2008. MORLAND, Iain. Intimate Violations: Intersex and the Ethics of Bodily Integrity. Feminism \& Psychology, v. 18 (3), p. 425-430, 2008.

2014.

. Intersex. TSQ: Transgender Studies Quarterly, v. 1, Mai., p. 111-115,

SOUZA LIMA, Antonio Carlos de. Sobre gestar e gerir a desigualdade: pontos de investigação e diálogo. In: (Org.). Gestar e Gerir: estudos para uma antropologia da administração pública no Brasil. Rio de Janeiro: Relume Dumará, p. 11-22, 2002.

PRECIADO, Paul (Beatriz). Testo Yonqui. Madrid: Espasa Calpe, 2008.

PINO, Nádia Perez. A Teoria Queer e os Intersex: experiências invisíveis de corpos des-feitos. Cadernos Pagu, v. 28, Jan-Jun., p. 149-174, 2007.

PIRES, Barbara. Distinções do Desenvolvimento Sexual: percursos científicos e atravessamentos políticos em casos de intersexualidade. Dissertação. (Mestrado em Antropologia Social) Programa de Pós-Graduação em Antropologia Social, Museu Nacional, Universidade Federal do Rio de Janeiro, 2015.

ROHDEN, Fabíola; RUSSO, Jane; GIAMI, Alain. Novas tecnologias de intervenção na sexualidade: o panorama latino-americano. Sex., Salud Soc., Rio de Janeiro, n. 17, Aug., p. 10-29, 2014.

SPEISER, Phyllis W; AZZIZ, Ricardo; BASKIN, Laurence S; GHIZZONI, Lucia; HENSLE, Terry W; MERKE, Deborah P; MEYER-BAHLBURG, Heino F L; MILLER, Walter L.; MONTORI, Victor M; OBERFIELD, Sharon E; RITZEN, Martin; WHITE, Perrin C. A Summary of the Endocrine Society Clinical Practice Guidelines on Congenital Adrenal Hyperplasia due to Steroid 21-Hydroxylase Deficiency. International Journal of Pediatric Endocrinology, n. 1, 2010.

STRATHERN, Marilyn. A pessoa como um todo e seus artefatos. In: STRATHERN, Marilyn. O efeito etnográfico e outros ensaios. São Paulo: Cosac Naify, 2014.

TELLES-SILVEIRA, Marina; TONETTO-FERNANDES, Vânia F; SCHILLER, Paulo; KATER, Claudio E. Hiperplasia adrenal congênita: estudo qualitativo sobre doença e tratamento, dúvidas, angústias e relacionamentos (parte I). Arq Bras Endocrinol Metab, São Paulo, v. 53, n. 9, 2009. 